\title{
LA INTERACCIÓN SOCIAL EN GOFFMAN
}

\author{
Juan José Caballero
}

Universidad Complutense de Madrid

\section{RESUMEN}

Se afirma en este artículo que Goffman es uno de los grandes científicos sociales de la segunda mitad de este siglo y, sin duda, el gran estudioso de la interacción cara-a-cara (él prefiere hablar del «orden de la interacción" o de la "co-presencia»), aunque no resulte admisible intentar autonomizar este orden de la interacción (como parece intentar Goffman). Comienza el artículo con una descripción de la trayectoria intelectual de Goffman y de las obras fruto de esa trayectoria. Se examinan después con algún detalle dos de sus obras más representativas: The Presentation of Self in Everyday Life y Frame Analysis. Se estudia a continuación la conversación y sus aspectos rituales. Considera el quinto apartado el alcance teórico de la obra de Goffman. Termina el artículo con la exposición de algunas de las diversas críticas que se han hecho a Goffman. Y es que Goffman sólo cuenta (y muy bien) una parte de lo que en la vida social sucede: la de la interacción cara-a-cara, con su innegable especificidad y su relativa autonomía. Pero hay otra parte (la de las diferencias de poder, la de los sentimientos humanos, la del orden macro) que Goffman no cuenta ni pretende contar.

No parece exagerado afirmar que Erving Goffman es uno de los primeros sociólogos del último medio siglo. Sus escritos han sido casi universalmente aclamados por su luminosidad, su encanto y su perspicacia. Pero no se suele incluir a Goffman entre los grandes teóricos de la sociología reciente. Giddens (en su admirativo artículo, de 1987, "Erving Goffman as a systematic social theorist») considera que esto es injusto y que Goffman debe ser considerado 
como uno de los grandes teóricos de la sociología de nuestro tiempo (al mismo nivel, dice, que gentes como Parsons, Merton, Foucault, Habermas o Bourdieu), cabiendo extraer de sus escritos un verdadero sistema de teoría social. Piensa Giddens que el que no haya acuerdo sobre esto se debe fundamentalmente a dos razones: 1) la propia pretensión intelectual de Goffman, quien (quizás con un exceso de humildad y rigor) evitó cuidadosamente lo relativo a la gran escala (lo macro) y al largo plazo; 2) a que a los escritos de Goffman les falta una cierta acumulatividad, siendo casi todos los libros colecciones de ensayos (Giddens, 1987: 110).

Los escritos de Goffman han sido interpretados erróneamente con bastante persistencia, en parte por culpa del mismo Goffman, pero también en parte por una tendencia de sociólogos más "ortodoxos» a ignorar el interés del pensamiento de Goffman para sus propios objetivos. Y es que Goffman publicó sus primeras obras cuando el positivismo y el funcionalismo estaban vigentes. Y su obra no encajaba en ese modelo, que tendía a considerarla ingeniosa pero frívola, light, incompatible con «la solidez y el cientifismo» del positivismo funcionalista. Como acabamos de decir, el mismo Goffman contribuyó a este planteamiento al considerar que se estaba moviendo en un determinado campo de estudio que tenía pocas implicaciones directas para las áreas centrales de la sociología. Así, comenta en Frame Analysis (probablemente su obra más sistemática) que su estudio no se refiere a la organización de la sociedad. Parece pensar que las fuerzas que de algún modo crean las características estructurales de los sistemas sociales son muy distintas de las actividades de los individuos en su vida diaria. Por tanto, los escritos de Goffman encajan cómodamente en la división entre lo micro y lo macro tan característica de una buena parte de la sociología actual. Califica a menudo Goffman a su obra de «microsociológica», pareciendo sentirse a gusto bajo tal etiqueta.

Hay cuatro aspectos en los que los escritos de Goffman han solido ser mal interpretados (Giddens, 1987: 111-114).

En primer lugar, se afirma a menudo que la obra de Goffman no es más que una serie de observaciones idiosincrásicas sobre rasgos triviales de la vida social, observaciones que, aunque brillantes e irónicas, no tienen unidad intelectual. Considera Giddens que esta afirmación es falsa y que Goffman se ocupa, desde sus primeros escritos, de una serie de cuestiones que surgen en toda su obra. Preocupa a Goffman el estudio de la interacción social, que "puede ser estrechamente identificada con la que surge únicamente en las situaciones sociales (es decir: en los contextos en los que dos o más individuos están físicamente en mutua presencia)... Mi preocupación a lo largo de los años ha sido la de promover la aceptación de este ámbito cara-a-cara como un ámbito analíticamente viable (ámbito que puede llamarse, a falta de una denominación mejor, el orden de la interacción), ámbito cuyo mejor método de estudio es el micro-análisis» (Goffman, 1983: 2; citado en Giddens, 1987: 111-112).

En segundo lugar, se sugiere a veces que Goffman no es sino un observador cínico de las costumbres de los americanos blancos de clase media. Se dice que las 
observaciones de Goffman sólo son aplicables a las actividades egoístas de los individuos que viven en un entorno cultural competitivo e individualista. Pero Goffman piensa, y parece que con razón, que las formas de actividad y los mecanismos sociales que describe son muy generales, siendo a menudo aplicables a la interacción social en todos los tiempos y lugares. Además, la obra de Goffman contiene toda una serie de términos de uso general.

En tercer lugar, se suele considerar que los actores de Goffman son exclusivamente "performers» (es decir: «actuantes» o actores en el sentido teatral del término, y no actores en el sentido aséptico o neutro en el que las ciencias sociales utilizan este término, considerando a los actores como simplemente los sujetos de cualquier acción social). En este sentido, los escritos de Goffman parecen simplemente un retrato de una cultura en la que la apariencia lo es todo y los individuos egoístas predominan. Sin embargo, piensa Giddens, ni Goffman es un observador desilusionado de los modos de actividad que analiza ni es la conducta de los individuos que estudia especialmente egoísta. Considera Giddens que Gouldner (de quien nos ocuparemos ampliamente más tarde a este respecto) se equivoca cuando afirma que la obra de Goffman se refiere no sólo a determinados sectores de la sociedad americana, sino a esa sociedad en una determinada fase de su desarrollo (la fase que sucede a la decadencia de la disciplina moral suministrada por la ética protestante). Consideran, pues, Gouldner y otros que Goffman pinta un universo social amoral, en el que cada cual trata de manipular a los demás. Giddens, por el contrario, considera que Goffman no sólo describe un mundo de relaciones sociales muy moralizado, sino que, además, tiende fuertemente a generalizar su naturaleza moral. Piensa que la confianza y el tacto son rasgos más fundamentales y vinculantes de la interacción social que la cínica manipulación de las apariencias.

$Y$, en cuarto y último lugar, la obra de Goffman es a menudo equivocadamente presentada como si fuese una etnografía (una antropología de la cultura). Si se identifica el método antropológico con un estudio cualitativo a pequeña escala, basado en la "observación participante», entonces los escritos de Goffman tienen, sin duda, un claro sello antropológico. Pero no conviene exagerar esto. $\mathrm{Y}$ es que, si bien la tesis doctoral de Goffman (sobre una comunidad de una isla Shetland) es claramente antropológica, no sucede lo mismo con sus estudios subsiguientes. Por ejemplo, Goffman no realiza comparaciones interculturales con respecto al material que trata y a los ejemplos que presenta. Es cierto que a Goffman le interesa lo exótico, pero no en el sentido de la etnología comparativa. Busca lo exótico dentro de lo familiar, intentando contemplar con distanciamiento intelectual lo más cotidiano y corriente de nuestras actividades diarias. Cuando Goffman quiere caracterizar globalmente su obra, prefiere utilizar el ejemplo de la etología (y no el de la etnografía). Y es que en los grupos animales todo lo que sucede es el resultado de las influencias de la copresencia física. «Los etólogos — dice Goffman (1971: 54; citado en Giddens, 1987: 114)—, se ven forzados a terminar siendo estudiosos de la interacción cara-a-cara.» 
Pienso que los juicios de Giddens sobre Goffman son fundamentalmente correctos, aunque quizás pequen de alguna exageración en la valoración de su obra. Es cierto que, en cuanto a Goffman, «se ha tomado a menudo el rábano por las hojas", considerando que, al ser brillante, al tratar de cuestiones cotidianas, al no resultar manifiesto su sistematismo (bastante mayor que el que suele pensarse) y al manejar ampliamente diversas fuentes literarias, debia tratarse de un autor perspicaz, sin duda, pero de escaso calado. Pienso, por el contrario, con Giddens, que Goffman es un auténtico "peso pesado" de las ciencias sociales que, como tantos otros clásicos, hace lo que hace (y lo hace muy bien) y deja de hacer bastantes cosas. Es decir: es original e importante (profundizando como nadie en el estudio de la interacción cara-a-cara) y, claro, forzosamente incompleto. De todos modos, hablaremos más sobre estas cuestiones más adelante.

En las páginas que siguen, empezaré por contemplar la trayectoria intelectual de Goffman y las obras fruto de esa trayectoria. Pasaré después a examinar con algún detalle dos de las obras de Goffman: The Presentation of Self in Everyday Life y Frame Analysis. La primera, de 1959, es la primera obra de Goffman (basada en buena parte en su tesis doctoral) y la más conocida. La segunda, de 1974, es la penúltima obra de Goffman y quizás la más sistemática y de mayor contenido teórico. Con el examen de estas dos obras pienso se puede obtener una cierta visión de las principales ideas de Goffman. Estudiaré en cuarto lugar la conversación y sus aspectos rituales (poniendo de relieve la amplia utilización por Goffman, siguiendo a Durkheim, del concepto de ritual). Estudiaré a continuación, enlazando con las páginas precedentes, el alcance teórico de la obra de Goffman. El sexto y último epígrafe estará destinado a considerar algunas de las diversas críticas que se han hecho a Goffman.

\section{TRAYECTORIA INTELECTUAL Y OBRAS}

Me baso para este epígrafe en la importante obra del profesor emérito de la Universidad de Edimburgo Tom Burns (Erving Goffman, 1992: 7-13), uno de los mejores conocedores de la obra de Goffman.

\subsection{TRAYECTORIA INTELECTUAL}

Nace Goffman en 1922 en Manville, Alberta (Canadá). Procede de una familia de judíos ucranianos que emigran, junto con otros muchos rusos, al Canadá a fines del siglo pasado. La familia se traslada luego a Dauphin, Manitoba, donde el padre tiene una sastrería de cierta importancia. 
Tras cursar tres años del bachillerato superior en Winnipeg, entra Erving en la Universidad de Manitoba en 1939 (eligiendo química como asignatura central, major, para su grado de diplomatura, bachelor), pero deja sus estudios para ir a Ottawa a trabajar para el National Film Board de Canadá. Se gradúa finalmente, como bachelor, en 1945. Dadas sus buenas calificaciones, es admitido en el prestigioso Departamento de Sociología de la Universidad de Chicago (el mejor, junto con el de Columbia, de los Estados Unidos por aquellas fechas).

La influencia de la Universidad de Chicago en la formación antropológica y sociológica de Goffman va a ser decisiva. No estaban ya allí, claro, Thomas, Park, Burgess o Wirth, pero sí Everett Hughes, que va a ser el más influyente de sus maestros (siendo, por ejemplo, el que acuña el concepto de «institución total»). Otro de sus maestros va a ser el conocido antropólogo Lloyd Warner, que será uno de los supervisores de su tesis doctoral. Por diversas razones, se decide que realice el trabajo de campo en una isla Shetland. Encarga Warner a Goffman que realice un estudio de la estructura social de la comunidad isleña. Pero sucede que pronto encuentra Erving que lo que más le interesa son las relaciones entre los locales y los turistas en, y en los alrededores de, el hotel en el que vivía. También se interesa por los medios de comunicación un tanto crípticos, o codificados, que utilizan los isleños entre sí. Es en este período de Shetland cuando Goffman empieza a elaborar sus ideas sobre lo que cabría llamar una retórica de la conducta. Su primer artículo («Symbols of Class Status») significa un punto de partida con respecto a su fase antropológica (un adiós sobre todo a Lloyd Warner).

Completa su tesis doctoral ("Communication Conduct in an Island Community») en 1953. Parte del material de su tesis (sobre todo lo relativo a las reglas de interacción social y a los modos de presentación del yo) va a ser utilizado en su primera monografía: The Presentation of Self in Everyday Life (1959). En 1954 es contratado como «científico visitante» por el National Institute of Mental Health (NIMH), en Bethesda (cerca de Washington). Investiga allí como "observador participante», trabajando como celador. Obtiene entonces un material que le va a ser de gran utilidad en sus trabajos sobre los hospitales psiquiátricos (y, en general, sobre las instituciones totales). Pasa tres años en Bethesda.

En 1957 es contratado por el Departamento de Sociología de Berkeley. Hace allí rápida carrera, llegando a catedrático en 1962 (cuando tenía cuarenta años). Se amplían los intereses de Goffman en su fase de Berkeley. En sus escritos de finales de los sesenta y de los setenta aparecen en él dos nuevos intereses: la fenomenología y la etología. También revive un viejo interés suyo: la lingüística. Es hacia 1960 cuando surge en los Estados Unidos un claro interés por los estudios de Alfred Schutz (discípulo del fenomenólogo Hüsserl) sobre el significado (en lugar de sobre la causación) de la conducta humana. En consecuencia, los sociólogos y psicólogos sociales interesados por el pensamiento de G. H. Mead (y en general por el interaccionismo simbólico) empiezan a estudiar fenomenología (y, en menor medida, hermenéutica). En cuanto a la etolo- 
gía, su interés por ella le viene en gran parte por su contacto con el interesante antropólogo Gregory Bateson y su equipo de Palo Alto. Como consecuencia de su investigación psiquiátrica en el NIMH, entra Goffman en contacto, en Berkeley, con Bateson y su grupo (que estaban estudiando la enfermedad mental en el Veteran's Administration Hospital de Palo Alto). Durante los primeros años de Goffman en Berkeley, la atención de Bateson se estaba orientando hacia la etología, y este interés de Bateson va a influir en el nuevo interés de Goffman por esta ciencia. Finalmente, un primer interés de Goffman por la lingüística revive como consecuencia del impacto de la revolucionaria "gramática transformacional» de Chomsky (que causa estragos entre los científicos sociales a principios de los sesenta). En el caso de Goffman, esta influencia se ve reforzada por la presencia en Berkeley de John Searle y, más tarde, H. P. Grice. Estas tres recién citadas influencias (fenomenología, etología y lingüística) se empiezan a reflejar en sus escritos a fines de los sesenta.

Permanece Goffman en Berkeley hasta 1968, año en el que se traslada a la Universidad de Pennsylvania, donde trabaja en estrecho contacto con la importante escuela sociolingüística que allí había. Muere Goffman en 1982, a los sesenta años.

\subsection{OBRAS}

Los escritos de Goffman consisten en unas dos docenas de libros y artículos. Casi todos los artículos volvieron luego a ser publicados en cuatro colecciones de ensayos: Asylums (1961), Interaction Ritual (1967), Relations in Public (1971) y Forms of Talk (1981). Otros dos libros, Encounters (1961) y Strategic Interaction (1969), se componen de dos ensayos o previamente no publicados o revisados con respecto a su primera publicación y retitulados. Hay, por fin, cinco monografías publicadas, de entrada, como libros: The Presentation of Self in Everyday Life (1959), Stigma (1963), Behavior in Public Places (1963), Frame Analysis (1974) y Gender Advertisements (1979).

Los once libros de Goffman forman un cuerpo de escritos muy compacto, en contra de lo que se ha dicho a veces. Se ocupan de unos cuantos temas muy relacionados entre sí y hay también unidad y originalidad en cuanto a la metodología, el enfoque y el estilo literario. Los cambios más claros se van produciendo en la terminología (el aparato conceptual). Empieza siguiendo de cerca tanto las ideas como el enfoque metodológico de Durkheim y Simmel, pero tiende a abandonarlos durante los años sesenta. Va entonces utilizando conceptos desarrollados para el estudio de la conducta animal y va también sumergiéndose en el campo de la fenomenología (que se estaba poniendo de moda por entonces en la sociología). Finalmente, durante los años setenta y hasta su muerte (1982), vuelve, como ya hemos dicho, a su interés primerizo por la lingüística, utilizando ampliamente tanto las ideas como la terminología de Chomsky, Searle y Grice. 
En cuanto al material empírico propio manejado por Goffman, éste procede tanto de su tesis doctoral en Shetland (que utiliza ampliamente, como ya se ha dicho, en The Presentation of Self..., aunque sigue haciendo referencias ocasionales a esta investigación durante los quince años siguientes) como de sus tres años de investigación en el National Institute of Mental Health de Bethesda (utiliza ampliamente este material a lo largo de toda su vida).

Todos los escritos de Goffman se refieren a la sociedad americana de su tiempo, en la que estudia con cuidado los más variados aspectos de la interacción social. Pero, aun ocupándose fundamentalmente de lo que él llama la «microsociología» de la interacción social, trata también ampliamente el «sí mismo" de los individuos y los aspectos de la estructura social más relevantes para sus temas centrales. Se ocupa, pues, Goffman de la interacción social (sobre todo), del sí mismo y del orden social. En The Presentation of Self... presenta Goffman la conducta individual como actuación histriónica. Dos ensayos posteriores, «Role Distance» y "Where the Action Is», complementan y modifican esta visión del sí mismo individual. En los ensayos de Asylums, y en otros dos ensayos («Mental Symptoms and Public Order» y «The Insanity of Place»), afronta Goffman el tema de la enfermedad mental y de los hospitales psiquiátricos (aunque ya se había ocupado de estos temas en escritos anteriores). En Stigma y en Gender Advertisements trata de otros aspectos de la discriminación en general y de la subordinación. Finalmente, en Frame Analysis y en Forms of Talk vuelve a centrarse en su gran tema, la interacción social, tratándolo más refinadamente (con aportaciones de la etología, la fenomenología y la lingüística) y con mayor consideración del papel del sí mismo en el proceso interactivo.

\section{LA PRESENTACIÓN DEL YO EN LA VIDA COTIDIANA}

Es éste el libro más famoso de Goffman y su primer libro completo (no colección de ensayos). Lo publica en 1959. Se suele decir que se contiene aquí el modelo "dramatúrgico" de la sociedad. La vida es como el teatro en cuanto que consiste en actuaciones (performances), habiendo actores y público. Lo que se representa en el escenario es tenido por real mientras dura la representación. Parece este enfoque radicalmente relativista, al considerar la realidad integrada por momentos pasajeros de construcción social que desaparecen cuando termina la representación. Pero Goffman quiere que se tome su modelo de un modo más durkheimiano. La dramaturgia es un ritual. Crea un sentido de realidad compartida, realidad que no es forzosamente efímera. En la medida en la que el ritual tiene éxito, crea símbolos sociales llenos de fuerza moral. Los participantes salen de un ritual creyendo en los símbolos, al menos durante cierto tiempo. La realidad social no es sólo construida, sino también reproducida y mantenida. Cabe, pues, decir que los rituales tienen un carácter coercitivo.

Dividiremos el estudio de esta obra en tres partes. Trataremos en primer lugar la presentación del yo siguiendo muy de cerca el prefacio y la introduc- 
ción de la obra (Goffman, 1959: IX y X y 1-14). Hablaremos en segundo lugar de las actuaciones o representaciones (performances). Repasaremos, finalmente, de modo telegráfico, los conceptos que Goffman maneja en esta obra no aparecidos anteriormente.

\subsection{LA PRESENTACIÓN DEL YO}

Veamos lo que nos dice Goffman justo al comienzo de su obra: «la perspectiva utilizada en este informe es la de la representación teatral; los principios derivados son dramatúrgicos. Consideraré: el modo cómo el individuo, en situaciones normales de trabajo, se presenta a sí mismo y presenta su actividad a los demás; los modos cómo guía y controla la impresión que ellos forman de él; y el tipo de cosas que puede o no que haga mientras realiza su representación delante de ellos... en el escenario, un actor se presenta como personaje a personajes representados por otros actores; la audiencia constituye una tercera parte en la interacción... En la vida real, las tres partes se funden en dos; el papel que un individuo desempeña se ajusta a los papeles representados por los demás presentes, y sin embargo estos otros constituyen también la audiencia» (Goffman, 1959: IX).

"Cuando un individuo entra en presencia de los demás, ellos normalmente buscan adquirir información sobre él o utilizar información sobre él que ya tienen. Se interesarán por: su status socioeconómico general, su concepción de sí mismo, su actitud hacia ellos, su competencia, su fiabilidad, etc. Aunque alguna de esta información parece ser buscada casi como un fin en sí misma, hay usualmente razones muy prácticas para adquirirla. La información sobre el individuo ayuda a definir la situación...» (p. 1).

«La expresividad del individuo (y por tanto su capacidad para producir impresiones) parece implicar dos tipos radicalmente distintos de actividad señalizadora (sign activity): la expresión que produce (gives) y la expresión que se le escapa (gives off). La primera implica símbolos verbales, o sus sustitutos, que utiliza únicamente para transmitir la información que se sabe que él y los demás conectan con estos símbolos. Es ésta comunicación en el sentido tradicional y estricto. La segunda implica una amplia gama de acción que otros pueden tratar como sintomática del actor, suponiéndose que la acción fue realizada por razones distintas de la información de este modo transmitida. Como tendremos que ver, esta distinción sólo tiene una validez inicial. El individuo, desde luego, transmite intencionadamente información falsa por medio de estos dos tipos de comunicación, la primera implicando mentira y la segunda fingimiento" (p. 2).

«De los dos tipos de comunicación -expresiones producidas y expresiones "escapadas" - este informe se ocupará fundamentalmente de las segundas, del tipo más teatral y contextual, del tipo no verbal, y presumiblemente no intencional, se realice o no intencionalmente esta comunicación» (p. 4).

«Independientemente del objetivo concreto que el individuo tenga en la 
cabeza y de su motivo para tener este objetivo, le interesará controlar la conducta de los demás, especialmente las respuestas que le den. Este control se consigue fundamentalmente influenciando la definición de la situación que los otros formulan... Así, cuando un individuo aparece en presencia de otros, habrá normalmente alguna razón para que movilice su actividad de modo que produzca en los demás una impresión que le interese producir» (pp. 3-4).

«... cuando un individuo aparece delante de otros, sus acciones influirán sobre la definición de la situación que ellos realizan. A veces el individuo actuará de un modo plenamente calculador... A veces el individuo será calculador en su actividad pero no se dará mucha cuenta de que esto sucede. A veces se expresará, intencional y conscientemente, de un cierto modo, pero principalmente porque la tradición de su grupo o de su status social exige este tipo de expresión y no a causa de ninguna respuesta concreta (distinta de una vaga aceptación o aprobación) que es probable se produzca en los impresionados por la expresión. A veces las tradiciones del rol de un individuo le llevarán a dar una clara impresión de un cierto tipo, aunque puede que no esté dispuesto, consciente o inconscientemente, a crear tal impresión» (pp. 5-6).

"Hay un aspecto de la respuesta de los demás que merece aquí especial comentario. Sabiendo que el individuo es probable se presente de un modo que le resulte favorable, los demás pueden dividir lo que presencian en dos partes: una parte que resulta relativamente fácil para el individuo manipular a su capricho, parte que consiste fundamentalmente en sus enunciados verbales, y una parte con respecto a la cual parece tener poco interés o poco control, parte que deriva principalmente de las expresiones que se le escapan» (p. 6). "Ahora bien, dado que los otros es probable que comprueben los aspectos más controlables de la conducta por medio de los menos controlables, cabe esperar que a veces el individuo trate de explotar esta posibilidad, guiando la impresión que causa mediante una conducta que se piensa es claramente reveladora" (p. 7). "... el arte de "calar" el esfuerzo de un individuo por dar la impresión de que no actúa intencionalmente parece estar más desarrollado que nuestra capacidad para manipular nuestra propia conducta, de modo que... es probable que el otro tenga ventaja sobre el actor» (p. 8).

"Cuando consideramos que el individuo proyecta una definición de la situación cuando aparece ante otros, tenemos que tener en cuenta que los otros... proyectarán también una definición de la situación por medio de su respuesta al individuo y por medio de las líneas de acción que inicien hacia él.» "Además, hay habitualmente una especie de división del trabajo definicional. Se permite que cada participante "lleve la voz cantante" con respecto a las cuestiones que le resulten vitales pero que no son inmediatamente importantes para los demás (v. g., las racionalizaciones y justificaciones mediante las que da cuenta de su actividad pasada).» "Tenemos, pues, una especie de modus vivendi interaccional. Los participantes contribuyen conjuntamente a una definición de la situación única y global que implica no tanto un acuerdo real sobre lo que existe sino más bien un acuerdo real sobre qué pretensiones (de quiénes y 
sobre qué cuestiones) serán de momento aceptadas. Llamaré a este nivel de acuerdo "consenso operativo"» (pp. 8-9).

«Dado que el individuo proyecta eficazmente una definición de la situación cuando entra en presencia de los otros, podemos suponer que pueden surgir en la interacción hechos que contradigan, desacrediten o pongan de otro modo en duda esta proyección. Cuando se producen estos hechos disruptivos, puede producirse una confusa y embarazosa interrupción en la interacción misma» ... "En tales momentos, el individuo cuya presentación se ha visto desacreditada puede sentirse avergonzado mientras que los demás presentes pueden experimentar hostilidad, y todos los participantes pueden sentirse incómodos ..., experimentando el tipo de anomalía que se genera cuando se rompe el minúsculo sistema social de la interacción cara-a-cara» (p. 11).

"Al subrayar que la definición inicial de la situación proyectada por un individuo tiende a suministrar un plan para la actividad cooperativa que sigue (al subrayar, pues, este punto de vista accional), no debemos descuidar el hecho crucial de que cualquier definición proyectada de la situación tiene también un distintivo carácter moral. Es este carácter moral de las proyecciones del que nos ocuparemos principalmente en este trabajo. La sociedad está organizada sobre la base de que cualquier individuo que tiene ciertos rasgos sociales tiene un derecho moral a esperar que los demás lo valorarán y lo tratarán de un modo adecuado. Conectado a este principio está un segundo principio: que un individuo que implícita o explícitamente da a entender que tiene ciertos rasgos sociales debe ser de hecho lo que pretende ser» (ibidem).

«Para resumir, pues, supongo que cuando un individuo aparece delante de otros tendrá muchos motivos para tratar de controlar la impresión que ellos reciben de la situación. Este trabajo se ocupa de algunas de las técnicas corrientes que las personas utilizan para mantener tales impresiones y de algunas de las contingencias usuales asociadas al empleo de estas técnicas» (p. 13).

"Conviene terminar esta introducción con algunas definiciones implicadas en lo que antecede y necesarias para lo que sigue. A efectos de este trabajo, la interacción (es decir: la interacción cara-a-cara) puede ser aproximadamente definida como la influencia recíproca de los individuos sobre las mutuas acciones cuando están en mutua presencia física inmediata... Una actuación (performance) puede ser definida como: toda la actividad de un participante dado en una ocasión dada que sirve para influir de algún modo sobre cualquiera de los demás participantes. Tomando a un participante concreto y a su actuación (performance) como punto de referencia básico, podemos referirnos a los que realizan las otras actuaciones como audiencia, observadores o coparticipantes. La pauta de acción preestablecida que se despliega durante una actuación y que puede ser presentada o desplegada en otras ocasiones puede ser llamada "parte" (part) o "rutina". Estos términos situacionales pueden ser fácilmente relacionados con términos convencionales estructurales. Cuando un individuo o actor (performer) realiza la misma parte o papel ante la misma audiencia en distintas ocasiones, es probable que surja una relación social. Definiendo rol 
social como la realización de derechos y deberes ligados a un status dado, podemos decir que un rol social incluirá una o más partes...» (pp. 13-14).

\subsection{ACTUACIONES (PERFORMANCES)}

En el enfoque dramatúrgico de Goffman, la acción humana es una constante representación escénica por parte del actor individual. El actor desempeña un papel en presencia de una audiencia. El actor es un actuante (performer): presenta una actuación a una audiencia, la cual reacciona con aprobación o desaprobación.

Lo que Goffman proporciona en La presentación del yo... es una descripción fenomenológica de distintos aspectos de una actuación. Como muestra el título de este libro, la presentación del sí mismo del actor en la sociedad es el problema crucial en el que se centra el interés sociológico. El problema aquí es el de la interrelación entre la autorrealización, por una parte, y el cumplimiento de las prescripciones de los roles sociales, por otra. Explicaremos a continuación los diversos aspectos del desempeño de roles poniendo como ejemplo, dentro de un contexto educativo, a los profesores y a los alumnos (Münch 2, 1994: 310-316).

\subsubsection{Desempeño de roles sincero y cínico}

El rol de profesor está definido por las normas socialmente prescritas para la actuación en la posición de profesor y por las expectativas sociales que se dirigen hacia esa posición. El profesor actúa en un escenario. Los estudiantes, los otros profesores y la dirección del centro educativo constituyen la audiencia o público. Análogamente, el rol de estudiante es desempeñado ante una audiencia integrada por los otros estudiantes, los profesores y la dirección del centro.

Un profesor desempeña su papel sinceramente en la medida en la que cree en él. Un actuante sincero dice siempre que lo que piensa es verdadero, sin tener en cuenta las consecuencias que ello pueda tener para él o para otras personas (incluidos los miembros del público). Un profesor desempeña su rol o papel de un modo cínico en la medida en la que no cree en dicho papel. Lo normal suele ser un compromiso entre sinceridad y cinismo. La total sinceridad suele ser peligrosa. El profesor que, por ejemplo, muestra todas sus dudas ante sus alumnos puede correr peligro. El profesor puede, quizás, mostrar algunas de sus dudas, pero no todas, y relativizar otras. A menudo hay una separación entre un comportamiento sincero entre bastidores (por ejemplo, cuando un profesor habla con colegas) y un comportamiento un tanto cínico en el escenario (cara al público, a los alumnos). Puede incluso que entre bastidores el profesor bromee sobre su cínica actuación en la clase. 


\subsubsection{Fachada}

El desempeño del rol de profesor tiene lugar en un escenario que tiene una fachada (front). La fachada define la situación para la actuación, indicando qué tipo de desempeño de rol tiene lugar. Cabe hablar de dos tipos de fachada: fachada social y fachada personal. La fachada social es el contexto en el que se desempeña un rol. La fachada personal es la apariencia del actor y su modo idiosincrásico de desempeñar el rol. En nuestro ejemplo, la fachada social vendrá constituida por la puesta en escena de la clase: colocación de los asientos, atril del profesor y equipo que utiliza (pizarra, proyector, vídeo...)... La fachada personal del profesor viene constituida, en primer lugar, por su apariencia: sexo, edad, título, modo de vestir, modo de hablar, expresiones faciales y movimientos corporales... Algunos de estos elementos son relativamente fijos (sexo, edad, título). Otros pueden cambiar de una situación a otra (modo de vestir, modo de hablar, gestos). La fachada social consiste en los aspectos más generalizados y estandarizados del desempeño de roles, que el actor tiene que aceptar como pautas establecidas de dicho desempeño. La fachada personal está más abierta a la invención por parte del actor. Y es que cada actor desempeña su rol un tanto a su manera, siendo la relación entre rol y personalidad una concreción de la relación entre lo social (rol) y lo individual (personalidad).

\subsubsection{Escenario y bastidores}

Los escenarios en los cuales se representa el teatro de la vida cotidiana son lugares reales, físicos. La realidad se compone de estratos. El mundo material es el estrato básico. Sobre él, los individuos se encuentran en cuanto cuerpos físicos reales y realizan rituales que generan un segundo nivel de realidad: instituciones sociales y "sí mismos» socialmente construidos.

Los escenarios (frontstages) y los bastidores (backstages) son regiones, áreas de espacio físico. El escenario es el lugar donde tiene lugar la representación. Hay en él diversos accesorios (props), que buscan causar una cierta impresión y facilitar un cierto tipo de representación. Los bastidores son lugares no visibles desde el escenario. Es el lugar donde se guardan los instrumentos materiales para preparar el escenario y para limpiarlo después de la representación y donde se esconde la basura (además de la basura física, hay una basura social que también se oculta entre bastidores). Los bastidores son también el lugar donde los actores se reúnen antes y después de la representación, tanto para ensayar y planificar (antes) como para comentar y relajarse (después). A veces hay lugares específicos que sirven como escenarios (salones, salas de reunión, salas de exhibición comercial...) o como bastidores (cocinas, cuartos de baño, almacenes...). Pero el mismo lugar puede servir como escenario o como bastidores en distintos momentos (v.g., el cuarto de baño es especialmente limpiado para los invitados, la sala de reunión es barrida después de la reunión). 


\subsection{OTROS CONCEPTOS MANEJADOS EN LA PRESENTACIÓN...}

Pasamos a ocuparnos de algunos conceptos que aparecen en la obra que nos ocupa y a los que no nos hemos referido hasta ahora.

\section{Dramatización (Dramatic Realization)}

Se trata de que el actor tiene que presentar su actuación ante la audiencia de modo que quede subrayada la importancia de la acción para el público. Podríamos decir coloquialmente que "hay que vender el producto» (que es la actuación o representación en cuanto emanación del actor). En nuestro ejemplo educativo, el profesor intentará mostrar el carácter único de sus enseñanzas, para lo que, por ejemplo, utilizará todo lo posible sus propias investigaciones y publicaciones.

\section{Idealización}

Un actor que trata de ajustarse al desempeño ideal de un rol tiende a idealizar su desempeño del rol. En este caso, el actor subraya aquellas partes del desempeño del rol que se ajustan a la imagen ideal del rol y oculta aquellas otras partes que no se ajustan. El profesor, por ejemplo, tiene que ajustarse al ideal de tener grandes conocimientos sobre su tema. Cada señal dada de falta de conocimientos pondrá en peligro su autoridad en la clase, por lo que intentará ocultar sus ignorancias.

\section{Mantenimiento de control expresivo}

Un actor no mantiene control expresivo: 1) cuando pierde accidentalmente el control físico; y 2) cuando muestra demasiada preocupación por una interacción o, por el contrario, demasiado poca preocupación. En el primer caso, el profesor puede tropezar y caer en plena clase, quedando en posición un tanto ridícula, lo que tiende a disminuir su autoridad. Pero quizás sepa salir airoso del trance (por ejemplo, mediante una broma oportuna), con lo que su imagen puede mejorar (al mostrarse más humano).

En el segundo caso, el profesor puede prestar poca atención a la pregunta de un alumno o, por el contrario, preocuparse excesivamente por ella. Ambas reacciones resultarán inadecuadas. La primera, porque mostrará a un profesor poco preocupado por sus alumnos. La segunda, porque puede indicar que el profesor está poco seguro de sus conocimientos (o de sí mismo en general). 
Representación no veraz (misrepresentation)

Tiene lugar cuando un actor se expresa en su desempeño de rol de modo no conforme con la realidad: miente descaradamente, guarda secretos, rehúsa revelar hechos inconvenientes. El actor honrado evita la aplicación usual de estas técnicas, mientras que el no honrado las utiliza constantemente.

\section{Mistificación (mystification)}

Es un modo de colocar a un determinado actor por encima de los actores normales atribuyéndole cualidades excepcionales. Un modo concreto de mistificación es el establecimiento de distancia social entre el actor y la audiencia. El hecho, por ejemplo, de que los alumnos sólo suelen ver a sus profesores en clase o en su despacho presta a éstos una aureola de «sacerdotes del saber», desprovistos de cualquier pasión humana.

\section{Realidad y engaño (contrivance)}

Cualquier desempeño de rol se sitúa entre la veracidad y el engaño. Lo normal es que se dé una mezcla de ambas cosas. Y es que un eficaz desempeño de roles necesita tal mezcla: el actor honrado, sincero y serio necesita prestar tanta atención a una adecuada presentación de sí mismo como el actor deshonesto, no sincero y frívolo porque también aquél necesita «vender su producto» (el de su actuación).

\section{Equipos}

Un equipo es un conjunto de roles interrelacionados desempeñados ante una audiencia. El profesor y sus colegas constituyen un equipo que actúa ante su público (los alumnos). Para que el equipo resulte eficaz debe ser coherente, es decir: sus distintos miembros deben representar sus roles de modo mutuamente compatible.

\section{Roles discrepantes}

Se dice de los roles que son discrepantes cuando no se ajustan a los roles establecidos de un equipo, sino que actúan como informadores para otros equipos y/o para la audiencia. Ejemplos de roles discrepantes son el «submarino" (supuesto miembro de un partido político que en realidad trabaja para otro partido distinto) y el espía. 


\section{Comunicación fuera de carácter (communication out of character)}

Cuando distintos equipos se reúnen (v.g., representantes de distintos partidos políticos), suelen presentarse mutuamente apareciendo como pretenden ser. Es decir: permanecen "en carácter» (stay in character), juegan el juego oficial y hablan el lenguaje oficial. Sin embargo, cuanta más tensión experimentan al actuar así, más probable es que utilicen mecanismos para indicar que no son realmente lo que parecen ser cuando juegan el juego oficial. Se comunican entonces "fuera de carácter». Un equipo, por ejemplo, puede hablar entre bastidores sobre la audiencia de modo distinto a como lo hace en el escenario. Se puede, por ejemplo, ridiculizar, cuando abandonan la escena, a aquellos a quienes se trató muy seriamente mientras estaban presentes. Un último ejemplo puede ser el de equipos que interactúan oficialmente (v.g., partidos políticos, sindicatos y patronal...) y que, paralelamente, se comunican extraoficialmente de modo que se abran nuevas vías de entendimiento, comunicación ésta que no podría tener lugar hablando oficialmente ante una audiencia (es decir: "con luz y taquígrafos»).

\section{Manejo de impresiones (impression management)}

Un equipo necesita, para actuar eficazmente, lealtad dramatúrgica, disciplina y una visión global de la situación. Necesita también mecanismos defensivos: control de acceso al equipo (al que puede perjudicar el resultar demasiado fácilmente accesible), separación entre escenario y bastidores (del que ya hemos hablado) y tacto.

\section{FRAME ANALYSIS}

Es ésta la obra más sistemática y conceptual de Goffman (no traducida al español). Pertenece a su época tardía (1974). En ella se mezclan lo sociológico, lo filosófico (en su versión fenomenológica) y lo lingüístico. Como el subtítulo de la obra indica (an essay on the organization of experience), analiza en ella Goffman cómo los humanos organizamos nuestras experiencias. Su tema fundamental es el estudio del sentido de la realidad, subrayándose que un determinado hecho admite distintas interpretaciones. La palabra frame la traduciremos normalmente por marco o esquema interpretativo. Utiliza Goffman la metáfora de los marcos (frames) de distintos tamaños, encajados unos en otros. Podemos, pues, enmarcar nuestras experiencias de lo real de distintos modos. Otra metáfora que utiliza es la de las claves musicales (habla de keys y de keying), pudiéndose pasar de una clave a otra ("cambiar de chip», se dice hoy a veces de modo castizamente informático).

Un esquema interpretativo (frame) aplicado por una persona determina lo 
que sucede en una situación para esa persona. Un esquema interpretativo es un instrumento para observar y comprender lo que sucede. El enmarcamiento interpretativo (framing) de una situación significa percibir, interpretar y comprender esa situación, y a las acciones y a las personas implicadas en esa situación, de un cierto modo. El enmarcamiento interpretativo es un proceso de percepción, interpretación, comprensión y actuación. Consiste en definir una situación a la luz de sistemas simbólicos de significado, cogniciones, normas y perspectivas estéticas. El enmarcamiento conceptual de la percepción, la comprensión, la acción y la identidad mediante sistemas simbólicos es un tema común de cualquier tipo de enfoque hermenéutico-interpretativo y fenomenológico.

Los marcos interpretativos de Goffman suponen distintos niveles o estratos, unos situados sobre otros (o marcos dentro de marcos). La realidad es, pues, múltiple, pero hay una estructuración o jerarquización de esta compleja realidad porque unos marcos son más importantes que otros. Los principales niveles son los marcos o esquemas primarios y las transformaciones.

Los marcos primarios ("primary frameworks") consisten en: 1) el mundo natural de los objetos físicos en el que las personas viven (incluidos sus propios cuerpos), y 2) el mundo social de las otras personas y de las relaciones sociales.

\section{TRANSFORMACIONES}

Una secuencia de actividad correspondiente a estos marcos primarios puede transformarse de diversos modos. A veces las secuencias de actividad tienen un significado distinto del manifiesto o aparente. Algunos de los ejemplos que Goffman pone son los siguientes:

- Ficciones («make-believe»): una representación teatral, niños que fantasean...

- Competiciones: deportes competitivos, juegos de salón, apuestas...

- Ceremoniales: bodas, bautizos, servicios religiosos... (es decir: actividades en las que lo que importa es su significado simbólico).

- Repeticiones técnicas ("technical redoings"). Se trata de acciones que los individuos realizan de modo que la actividad misma puede ser ensayada, practicada u observada, sin haber una seria implicación en la actividad. Ejemplos: prácticas (para una representación teatral para un deporte, para una ceremonia...), exhibiciones, psicoterapia (en la que se analizan hechos pasados) y experimentos.

Las transformaciones pueden ser innumerables. Puede haber transformaciones de transformaciones (por ejemplo: alguien puede practicar para una representación teatral, que es sobre una boda, siendo todo ello un experimento; tenemos aquí cuatro niveles de transformación, a los que habría que añadir un 
quinto nivel: el de las actividades físicas de las personas implicadas). La realidad, pues, puede ser bastante complicada. Pero, afirma Goffman, las personas suelen manejar con soltura estas múltiples realidades (probablemente porque es algo que hay que hacer constantemente).

Hay un tipo de transformación al que Goffman llama fabricaciones. Se trata de casos en los que los individuos implicados tratan de crear falsas nociones sobre lo que está realmente sucediendo. Los ejemplos van desde el espionaje hasta el manejo de impresiones en la vida social. El manejo de impresiones se puede conseguir mediante un adecuado enmarcamiento de las propias acciones y de la propia identidad. La capacidad para definir y para enmarcar una situación de un modo favorable a los propios objetivos y a la identidad personal es clave del éxito en la interacción estratégica. Esta capacidad, sin embargo, sólo puede utilizarse cuando las circunstancias externas lo permiten. Un rasgo importante de estas circunstancias es el poder que un actor tiene para imponer su propia definición de la situación, por lo que los actores menos poderosos se verán obligados a huir de confrontaciones directas y a utilizar esquemas interpretativos que les permitan, al menos, satisfacer sus necesidades elementales. Cuando el poder está más repartido, la interpretación de las situaciones se convertirá en una contienda entre actores y grupos que utilizarán plenamente las diversas técnicas para interpretar situaciones del modo más favorable posible para sus objetivos (Collins, 1988: 292-293).

Puede a veces suceder que los marcos interpretativos queden rotos por algún suceso inesperado. Cuando sucede algo que rompe una representación, o simplemente no encaja en el marco interpretativo en el que intentamos estar en ese momento, normalmente tendemos a desatender ese suceso irruptor o a «repararlo» rápidamente. Cuando, por ejemplo, un perro irrumpe en una boda, habrá invitados que intentarán discretamente echarlo y otros que se esforzarán por despreocuparse de su presencia (también habrá otros, claro, que seguirán, regocijados, sus avatares). Pero hay también perturbaciones extremas que rompen por completo un determinado marco interpretativo, viéndose interrumpida la representación. Esto, que resulta sin duda muy molesto, demuestra que las realidades primarias son más poderosas que las más secundarias y elaboradas.

\section{LA CONVERSACIÓN Y SUS ASPECTOS RITUALES}

La obra de Goffman indica que toda la estructura de la sociedad, tanto el trabajo como la sociabilidad privada, se mantiene mediante rituales. Muestra, además, que esa estructura está estratificada ritualmente. El sí mismo es socialmente manejado mediante rituales en escenarios separados de los bastidores (el propio hogar, por ejemplo, especialmente el dormitorio y el cuarto de baño, sirve como bastidores donde ocultar los aspectos más humildes del actor). Esta regionalización del sí mismo tiene implicaciones para las relaciones sociales: las 
relaciones personales de los individuos son más íntimas cuando tienen lugar entre bastidores que cuando se producen en el escenario, cara al público. Incluso las situaciones más íntimas tienen una estructura ritual (por ejemplo, las mismas relaciones sexuales son, en buena parte, una representación escenificada).

Goffman analiza las situaciones como rituales centrados en el sí mismo. La misma conversación es un ritual. Encontramos rituales naturales incluso en las interacciones más usuales de la vida cotidiana. Está la reunión del grupo (normalmente dos personas), el foco compartido de atención (la intención de hablar) y un estado de ánimo compartido (que va surgiendo a medida que los participantes se absorben en el tema de la conversación). Inicialmente, el clima social puede consistir sólo en un deseo compartido de ser sociable. Luego, si la conversación tiene éxito, pueden surgir distintos posibles climas (de humor, de mutua simpatía, de irritación...) (Collins: 1988: 206-207).

El resultado del ritual conversacional es que crea un pequeño culto temporal, una realidad compartida consistente en aquello de lo que se habla. En la conversación se puede crear simbólicamente un mundo de ideas ajeno al inmediato contexto físico y referido, quizás, a otros lugares o abstracciones o fantasías diversas. Una vez en plena marcha, el ritual conversacional produce sus propias presiones sobre los participantes. Hay que respetar el tema de conversación y creer en él (al menos temporalmente) porque el tema es de momento algo sagrado a lo que hay que adorar. La conversación es un pequeño sistema social con sus propias reglas. Una conversación humorística, por ejemplo, se hace cada vez más graciosa, de modo que casi cualquier observación, introducida en el momento oportuno, se convierte en ocasión para reírse. Hay que respetar el clima que ha ido surgiendo en la conversación. No se trata de que lo que alguien dice sea o no cierto. Se trata de que las mutuas representaciones sean compatibles. Por tanto, se violará el ritual si se cuestiona demasiado rotundamente lo que alguien dice, o si se toma una broma demasiado literalmente, o si no se escuchan con un mínimo respeto las "fantasmadas» o las quejas de alguien. Goffman llega a decir que una conversación es un estado temporal de cuasi-psicosis, en el que la única realidad que cuenta es la que mantiene la relación entre los que hablan (Goffman, 1967: 113).

La teoría de Habermas (1984) de la competencia comunicativa no entiende bien la perspectiva ritualista de Goffman, considerando que los actores de Goffman sólo se esfuerzan, maquiavélicamente, por engañar a los demás. Considera Habermas que la comunicación sería más eficaz si fuese más veraz y sincera. Piensa Goffman, por el contrario, que en el mundo ideal de Habermas no serían posibles las relaciones sociales. Afirma que en las relaciones sociales reales lo que se dice no tiene por qué ser verdadero o sincero. De hecho, se arruinará una conversación si no se entra en el clima de "fantasmería», humor, reivindicatividad..., que ha ido surgiendo en el microcosmos de esa conversación. Pienso que Goffman tiene razón, ajustándose más que Habermas a lo que de hecho sucede. 
Por supuesto que no todas las conversaciones son igualmente absorbentes. Si los actores no pueden implicarse en un foco suficiente de atención y de estado de ánimo comunes, el ritual conversacional no arranca y no surge un vínculo social entre dichos actores. Además, rituales conversacionales que van bastante bien hasta un cierto momento pueden decaer por violaciones rituales (Goffman habla de "alienación de la interacción») o por otras causas. La misma distinción entre las ocasiones en las que la interacción funciona y aquellas en las que no funciona es la que crea líneas divisorias en la estructura social, separando a las personas que tienen fuertes vínculos sociales de aquellas que no los tienen. Se forma así la estructura de red de la sociedad (la organización de grupos de status, que diría Weber) (Collins, 1988: 207-208).

Pero sigamos ahora más de cerca la producción de la conversación (Giddens, 1987: 126-127, comentando a Goffman, 1981: 22 y ss.). Como venimos diciendo, el habla es el instrumento básico de los encuentros focalizados y la conversación es el prototipo del intercambio de expresiones implicado en el habla. Interesa para el análisis de Goffman utilizar el término habla más que el de lenguaje. $Y$ es que la palabra «lenguaje» sugiere un sistema formal de signos y reglas, mientras que la palabra "habla» se refiere más a la naturaleza situada de las expresiones y de los gestos implicados en la producción rutinaria de los encuentros. Los significados comunicados mediante el habla se organizan y especifican mediante toda la gama de sutilezas en el manejo de la voz y en la gesticulación facial (y corporal en general) que se suelen utilizar en las circunstancias de co-presencia. En sus primeros escritos, Goffman tanto anticipó como ayudó a conformar el desarrollo de lo que se ha venido a llamar después «análisis conversacional». En sus obras posteriores ha desarrollado un tratamiento propio del habla y de la interacción verbal.

Sólo una persona puede hablar en un determinado momento en una conversación, por lo que todas las conversaciones están organizadas en términos de procedimientos para la toma de turnos. Las expresiones de los que contribuyen a una conversación se producen en distintas etapas de una secuencia temporal. Lo que cada individuo dice no sólo se orienta hacia lo que se ha dicho antes, sino que suele anticipar contribuciones ulteriores a la conversación. La secuencia temporal se suele organizar dialógicamente, incluso en conversaciones donde hay varios participantes. Así, la mayoría de las conversaciones pueden estudiarse como compuestas por unidades dialógicas (con injertos de otros participantes en la conversación).

Dado que la naturaleza de la conversación es dialógica, dos o más turnos de conversación (los turnos son, para Goffman, las unidades del habla en una conversación) pueden funcionar como una unidad interaccional. Para analizar este fenómeno, Goffman habla de los movimientos (moves) que se hacen a lo largo de las secuencias de conversación entre los participantes. Un movimiento en una conversación es como una estrategia en un juego, teniendo normalmente un carácter ritualizado. Los movimientos incluyen silencios además de expresiones efectivas. Así, es muy distinto callar cuando a uno le toca hablar 
(cuando llega el propio turno) que hacerlo mientras otro habla (cuando lo normal es precisamente callar). Los movimientos pueden consistir en varias oraciones, pero también pueden consistir en breves interjecciones.

Goffman muestra, como vamos viendo, que no cabe pensar en la conversación sólo en términos de afirmaciones que esperan contestaciones. Muchos movimientos parecen suscitar respuestas, pero hay diversos modos como los individuos pueden expresar intenciones, suministrar aprobación o desaprobación o dar a conocer de otro modo su punto de vista sin implicarse directamente en la toma de turnos dentro de la conversación. Hay también que tener en cuenta que el habla cara-a-cara se produce en un contexto físico y social «lleno» (de cosas, quizás de personas) que juega un importante papel en la comunicación. Por todo esto, no suele ser muy relevante que las expresiones no suelan consistir en las oraciones «bien formadas» de las que se suele ocupar predominantemente la lingüística. Es, pues, un considerable error juzgar la naturaleza del habla en términos de modelos de lenguaje "perfecto». Sólo en circunstancias muy especiales (por ejemplo, en el habla de los locutores de radio o televisión) es esperable, y exigible, un habla impecable.

\section{ALCANCE TEÓRICO DE LA OBRA DE GOFFMAN}

A lo largo de su carrera, Goffman no quiso entrar en dos territorios que podrían resultarle atractivos. Por una parte, y a excepción de su trabajo sobre las instituciones totales (en el que, además, se centra en los efectos de dichas instituciones sobre la actividad individual), mantiene una estricta separación entre su obra y la de los sociólogos interesados en las propiedades macroestructurales de los sistemas sociales. Por otra, no quiere entrar demasiado a fondo en la explicación de la psicología del si mismo (aunque dice cosas interesantes y llamativas al respecto). Las causas de estas autolimitaciones de Goffman parecen claras. Y es que considera que el análisis de las situaciones de co-presencia constituye un campo sociológico autónomo, campo cuyos límites sólo cabe explorar prescindiendo de la mayoría de las cuestiones de las que se han ocupado tradicionalmente tanto los sociólogos como los psicólogos. Y sucede que la obsesiva preocupación de Goffman por las situaciones de co-presencia le lleva a subestimar la importancia de su teoría para los problemas sociologicos macroestructurales.

Expresa Goffman su perspectiva teórica en un articulo póstumo ("The interaction order», 1983). Proclama en dicho artículo su interés primordial por el orden de la interacción como "campo sustantivo por derecho propio». Pasamos la mayor parte de nuestra vida cotidiana, dice, en presencia de otros. $\mathrm{Y}$, además, no es sólo que la interacción cara-a-cara esté limitada en el espacio y en el tiempo (por lo que constituye un tema específico), sino que está fundamentalmente determinada por las exigencias de la misma situación de co-presencia. Pero no por esto hay que pensar, considera Goffman, que las propiedades de los gran- 
des colectivos no son sino el conjunto de lo que sucede en distintas situaciones de co-presencia. Y es que tal postura, según Goffman, confunde la situación en la que se producen las acciones con las consecuencias institucionales de dichas acciones. No cabe deducir del estudio de los encuentros sociales la forma institucional que tales encuentros, en cierto sentido, sustentan (Giddens, 1987: 131-132).

En el artículo citado, Goffman presenta su obra como una subdivisión de la sociología que tiene potencialmente implicaciones universales pero que, al mismo tiempo, es distinta de otros campos sociológicos principales y del análisis psicológico de la motivación. Pero Goffman no defiende adecuadamente esta postura a un nivel empírico. Y es que Goffman no ha mostrado nunca mucho interés por comprobar en qué medida son generalizables los procesos que trata, actitud que resulta poco satisfactoria: 1) es una de las principales razones por las que sus escritos han parecido menos sistemáticos de lo que lo son; y 2) compromete potencialmente la pretendida autonomía del orden interaccional.

Goffman tiene razón cuando se resiste a considerar que su obra esté intrínsecamente relacionada con el individualismo metodológico en cuanto perspectiva filosófica. La conducta de los individuos en situaciones de co-presencia no es más o menos real que la existencia de relaciones sociales y formas sociales más abarcadoras. También tiene razón cuando dice que la división que traza entre sus escritos y los que se ocupan de las propiedades estructurales de los sistemas sociales no reproduce la distinción micro-macro tal y como se suele formular usualmente. Es decir: es un error confundir las situaciones de co-presencia con los grupos pequeños, contraponiendo éstos a los grandes grupos o colectividades. Sin embargo, al identificar persistentemente su obra como "microsociológica», Goffman tiende a oscurecer la originalidad de su postura y, al mismo tiempo, palia algunas de sus limitaciones (Giddens, 1987: 134).

Demuestra Goffman perspicazmente que lo que parecen ser aspectos triviales $y$ poco interesantes de la conducta cotidiana resultan estar llenos de implicaciones para la interacción. Sin embargo, muchos de los rasgos que identifica tienen más que ver con la reproducción de las instituciones de lo que él admite. Reconoce varios tipos de circunstancias en los que puede haber efectos situacionales sobre las estructuras sociales. Uno de los ejemplos más claros es el del lenguaje. El habla no es sólo una expresión situada del lenguaje: es el medio principal por el que el lenguaje, globalmente considerado, existe. Las propiedades estructurales globales del lenguaje (es decir: las reglas y los procedimientos generalizados del uso del lenguaje) no son propiedades de sujeto individual alguno, sino de comunidades lingüísticas que se extienden ampliamente en el espacio y a lo largo del tiempo. Otro ejemplo puede ser el del tratamiento por Goffman de la utilización del tacto y de otros mecanismos de apoyo como un medio de mantener la confianza entre los individuos. Las personas co-presentes son mutuamente vulnerables. De ahí que, incluso entre extraños implicados en un encuentro casual y pasajero, tiendan a observarse formas de ritual que mantengan la confianza y el respeto mutuos. 
En sus estudios sobre la co-presencia, Goffman demuestra que la predecibilidad de gran parte de la vida social, incluso en un plano macroestructural, se organiza mediante las prácticas implicadas en lo que él llama el orden de la interacción. Considera que la co-presencia es una especie de experiencia, característica de gran parte de la vida cotidiana de la mayoría de las personas, en la que los otros son directamente accesibles y en la que el individuo se muestra también accesible (es decir: demuestra, como le gusta decir a Goffman, agencia). La interacción en situación de co-presencia es, claro, distinta de la interacción «mediada» (por la carta o el fax, el teléfono...). Los individuos llegan a cualquier situación concreta de co-presencia «llevando una biografía previa de tratos anteriores con otros participantes...», así como "con una amplia gama de supuestos culturales que se presumen compartidos" (Goffman, 1983: 4; citado en Giddens, 1987: 137). Por ello, para tener una idea adecuada de lo que sucede en las situaciones de co-presencia, habrá que integrar un análisis de tales situaciones con lo que las conecta en las continuas vidas de los individuos ( $\mathrm{y}$ de los grupos).

Por lo que venimos viendo, la obra de Goffman contribuye mucho más a una comprensión de las propiedades "macroestructurales» de lo que él mismo supuso. $\mathrm{Y}$ es que, aunque Goffman busca muy deliberadamente separar su orden de la interacción de las propiedades macroestructurales de los sistemas sociales (como decíamos al comienzo de este epígrafe), cabe conectar (aunque él no lo haga) sus análisis de la co-presencia con mecanismos de reproducción social que actúan a lo ancho del espacio y a lo largo del tiempo.

También decíamos al comienzo de este epígrafe que Goffman no quiere, en su empeño por preservar la autonomía del orden interaccional, entrar a fondo en cuestiones psicológicas (vemos, pues, a Goffman esforzándose por mantenerse en un terreno estrictamente psicosociológico, ajeno tanto a lo claramente sociológico como a lo claramente psicológico). En este sentido, se resiste a entrar en cuestiones de motivación. Por ello cabe decir que lo mismo que los escritos de Goffman son un tanto "planos», en cuanto que consideran al mismo nivel todas las interacciones, sin prestar especial atención a las interacciones entre los poderosos, que tienen grandes consecuencias para la producción de la estructura social (con lo que la fundamental dimensión del poder está basante ausente de la obra de Goffman), dichos escritos están también un tanto «vacíos», en cuanto que se despreocupan de la motivación por la que los actores actúan como actúan en la vida cotidiana. Goffman deja suficientemente claro que hay una persona unitaria tras los roles desempeñados en la diversidad de contextos sociales, pero su tratamiento de este sí mismo es un tanto rudimentario (aunque, sin duda, interesante). Una interpretación clásica de la motivación para la interacción es la de que las personas buscan formar contratos implícitos (resulta provechoso para todos el ajustarse en las mutuas transacciones a ciertas convenciones mutuamente acordadas). Otra interpretación clásica, y bastante distinta, es la de que dicha motivación deriva de la interiorización de algún tipo de consenso normativo global (que se aplica luego a las 
situaciones de interacción cara-a-cara). Goffman considera estas dos interpretaciones parciales (más que falsas). Hay, dice, «juegos de motivos mixtos» (mixed motive games) en la interacción, y los individuos se ajustan a las convenciones oportunas por muchas y diversas razones.

Ocupémonos, para terminar este apartado, del cambio social (Giddens, 1987: 139). ¿Tienen los escritos de Goffman alguna relevancia para los procesos de profunda transformación de las instituciones sociales? Aunque no lo parezca, la respuesta debe ser afirmativa. Y es que los profundos cambios sociales suponen alteraciones de las prácticas sociales cotidianas (es precisamente en el cambio de estas prácticas donde se manifiestan los grandes cambios sociales). En la medida en la que no aceptemos la formulación goffmaniana de la autonomía del orden interaccional, y pensemos más bien en la intersección de variados contextos de co-presencia (conectados por los caminos que los individuos trazan entre los contextos en los que viven sus vidas cotidianas), no resulta excesivo encontrar un parecido entre la obra de Goffman y la del conocido historiador francés Fernand Braudel. Goffman se concentra aparentemente en lo efímero, mientras que Braudel lo hace en las tradicionales pautas de vida de civilizaciones globales. Pero ambos aclaran la naturaleza de la vida social cotidiana y, más específicamente, los modos como la actividad social cotidiana está implicada en pautas muy amplias de reproducción institucional. Hay procesos de cambio a largo plazo que están implicados en, y que se expresan a través de, las mismas contingencias de tal reproducción.

\section{ALGUNAS CRÍTICAS A GOFFMAN}

Goffman ha sido criticado desde una perspectiva teórica, metodológica e ideológica. Se ha dicho que en su obra: no hay una teoría explícita, sino sólo un vago marco de referencia; hay poco interés por los esquemas explicativos, aunque haya un brillante análisis descriptivo; falta solidez empírica, aunque haya alusiones, impresiones, anécdotas e ilustraciones iluminadoras; y, finalmente, hay escasas cualificaciones y reservas, de modo que no están claros los límites de la generalizabilidad.

Consideran muchos críticos que las imágenes de Goffman sugieren una visión sórdida y desencantada de los humanos y de su sociedad. Se afirma que esta visión significa la subordinación de la realidad a las apariencias, de la moralidad al oportunismo, considerándose al ser humano «un amoral mercader de moralidad» o un «despegado y racionalista manejador de impresiones» $\mathrm{y}$ al sí mismo «una pura mercancía».

Lyman y Scott (1970: 20) concretan brillantemente lo recién dicho utilizando los títulos de varios de los escritos de Goffman: «el actor social de Goffman, como el príncipe de Maquiavelo, vive externamente. Se implica diariamente en una ronda de manejo de impresiones, presentándose ventajosamente 
cuan de la es posible y "salvando los muebles" en las malas actuaciones. Su vida cotidiana consiste en rituales de interacción, empleando deferencia y manteniendo un cierto porte, salvando su cara y la de algún otro, inhibiendo acciones que destruirían la gracia de los juegos sociales, siendo íntimo cuando la ocasión lo exige y manteniendo la distancia cuando la proximidad resulta poco recomendable y, en general, adaptándose continuamente a las exigencias de la conducta en lugares públicos».

Algunos críticos han cuestionado la idea goffmaniana de la necesidad funcional de "actuaciones» para el mantenimiento del orden social (Collins y Makowsky, 1972: 212). Según ellos, la creciente informalidad de las relaciones interpersonales modernas y la erosión de los rangos en la sociedad americana contemporánea suscitan dudas sobre la medida en la que tales rituales son esenciales para la vida social. En cualquier caso, parece haber buenas razones para dudar sobre la ubicuidad en los asuntos humanos del frío y calculador manejo de impresiones.

Herbert Blumer (1972: 52), comentando una de las obras de Goffman (Relations in Public, 1971), muestra admiración tanto por este trabajo como por la obra de Goffman en general, pero hace al mismo tiempo algunas importantes críticas: "ha limitado el área a la asociación cara-a-cara, con una congruente exclusión de la gran masa de actividad humana que cae fuera de tal asociación. Además, ha limitado su estudio de la asociación cara-a-cara a la interacción entre posiciones personales, a costa de desentenderse de lo que los participantes están haciendo». El enfoque dramatúrgico ignora, pues, el macrocosmos en el que se inserta el nivel micro por él estudiado. Análogamente, el enfoque se desentiende del verdadero contenido sustantivo de los encuentros humanos, al preocuparse exclusivamente por las formas expresivas de los encuentros. La imagen resultante de la condición humana es claramente parcial.

Se ha dicho también que el dirigir la atención sociológica hacia las apariencias sociales (como lo hace Goffman) deriva de la sociedad de masas, con su producción masiva, su "marketización» masiva y su manipulación masiva de los gustos. Como dice Don Martindale (1960: 79): "desde los días de James, Cooley y Mead, se han aclarado gradualmente las plenas implicaciones de la sociedad de masas... El análisis se desplaza hacia las apariencias sociales y tiene lugar en términos de roles, actos, escenas e incidentes. El hombre como oportunista, más que como agente moral, es visualizado en el centro de su trama. Quedan excluidas de la nueva teoría tanto la visión religiosa como la visión humanística del hombre».

Como se ha ido diciendo, es crítica generalizada a Goffman la de que, al contemplar la sociedad actual, se fija en lo episódico o situacional, en el microanálisis de los breves encuentros, desentendiéndose de las circunstancias históricas o de los marcos institucionales. De todos modos, este rasgo lo comparte Goffman con la mayor parte del interaccionismo simbólico contemporáneo.

Hay también, claro, visiones más favorables de Goffman. Brittan, por ejem- 
plo, considera que las actuaciones dramáticas no son privativas de la sociedad de nuestro tiempo, sino que son un rasgo de toda interacción, tanto en sociedades remotas como en sociedades contemporáneas. R. Collins y M. Makowsky, ya citados, son claros admiradores de Goffman, alabando la perspectiva dramatúrgica por hacer de la conducta social «el foco central de atención, no en irreales situaciones de laboratorio sino en encuentros reales que constituyen la sustancia de la sociedad»(1972: 213). También A. Giddens, como hemos ido viendo, es un gran admirador de Goffman, al que considera uno de los primeros científicos sociales de la segunda mitad de nuestro siglo.

Veamos finalmente lo que sobre Goffman nos dice el sociólogo Alvin Gouldner (1920-80) en su ambiciosa y conocida obra de 1970 The Coming Crisis of Western Sociology (378-390), de la que extraigo a continuación múltiples citas (para aprovechar la brillante prosa de Gouldner).

\section{LA VISIÓN DE GOULDNER}

«... el modelo dramatúrgico presenta una visión en la que la vida social es contemplada sistemáticamente como una forma elaborada de drama y en la cual, como en el teatro, todos los hombres se esfuerzan por proyectar a los demás una imagen convincente de sí mismos. Aquí los hombres no son vistos como individuos que intentan hacer algo sino como individuos que intentan ser algo". "... lo que se considera real no es el trabajo que los hombres realizan o las funciones sociales que desempeñan. La conducta humana es más bien vista como esencialmente preocupada por fomentar y mantener ante los demás una concepción específica del sí mismo». ... «El valor de un hombre en este mundo, pues, depende de sus apariencias y no, como sucedía con el clásico burgués, de sus talentos, capacidades o realizaciones» (Gouldner, 1970: 380).

«Los actores de Goffman son activos gestores de la ilusión del sí mismo. Lo que ha sucedido, pues, no es que hayamos dejado el mundo del burgués sino que hemos entrado a fondo en el mundo distinto del nuevo burgués. El modelo dramatúrgico refleja el nuevo mundo, en el que un estrato de la clase media ya no cree que el trabajo duro es útil o que el éxito depende de la diligente aplicación. En este nuevo mundo hay una clara conciencia de la irracionalidad de la relación entre el logro individual y la magnitud de la recompensa, entre la aportación efectiva y la reputación social.» ... «La dramaturgia marca la transición entre una vieja economía centrada en la producción y una nueva economía centrada en la "marketización" y la promoción masivas, incluida la "marketización" del sí mismo... En esta nueva "economía terciaria", con su proliferación de servicios, los hombres producen crecientemente "actuaciones" más que cosas» (p. 381).

Considera Gouldner que los hombres modernos es probable que sean trabajadores o clientes de organizaciones burocráticas a gran escala sobre las que tienen poca influencia, siendo escasa su capacidad para cambiarlas. Además, en 
dichas organizaciones los individuos tienden a convertirse en unidades fácilmente intercambiables, con lo que disminuye su sentimiento de valía y de poder. Como consecuencia de esta alienación organizacional, los individuos dirigen sus esfuerzos hacia un manejo de impresiones que mantenga o incremente su status. Es probable que estos esfuerzos sean hechos especialmente, afirma Gouldner, por personas que tienen orientaciones individualistas y competitivas hacia la vida, pero que dependen para vivir de organizaciones a gran escala.

«La dramaturgia de Goffman es una necrológica de las viejas virtudes burguesas y una celebración de las nuevas. Ésta es su diferencia más fundamental con la teoría de Parsons, que permanece enraizada en las clásicas virtudes burguesas: en la creencia en la importancia tanto de la utilidad como de una moralidad auténtica. La sociología de Goffman no cree en ninguna de las dos, al menos en su sentido tradicional. Para Goffman, lo que cuenta no es si los hombres son morales, sino si parecen morales a los demás... Además, no es la utilidad de los hombres o sus actividades... lo que se considera importante. Lo que cuenta es si la apariencia es aceptable para, o deseada por, otros (es decir: si se puede vender), y no si la apariencia tiene relación alguna con una utilidad subyacente. Cabe decir que el funcionalismo se basaba en una concepción de los hombres y de sus actividades como "valores de uso" mientras que la dramaturgia se basa en una concepción de ellos sólo como "valores de cambio"... La dramaturgia alcanza y expresa la naturaleza del sí mismo como pura mercancía, completamente desprovista de cualquier valor de uso necesario: es la sociología de la venta del alma... La dramaturgia de Goffman es, pues, antiutilitaria sólo en el sentido de que se opone a una forma de utilitarismo ahora en declive histórico. Aún alienada de esta vieja forma..., usufructúa un nuevo utilitarismo "marketológico"; cree en la utilidad de las puras apariencias: en la presentación y el manejo del sí mismo" (p. 383).

«La dramaturgia de Goffman es un nuevo esfuerzo por resolver la tensión entre utilidad y moralidad; y responde a este dilema no aferrándose tenazmente a sus dos cuernos sino soltando ambos. Goffman, simple y diestramente, esquiva la cuestión, sustituyendo tanto la moralidad como la utilidad por la perspectiva de una estética sociológica. A pesar de esto, sin embargo, su solución sienta como premisa la existencia continuada del utilitarismo individualista y social, así como de los estratos sociales en los que se basa... La sociología de Erving Goffman es, en mi opinión, una expresión teórica complejamente articulada en la que resuena la nueva experiencia de la clase media educada. Esta nueva experiencia ha generado nuevas concepciones sobre lo que es "real" en el mundo social, junto con una nueva estructura de sentimientos y supuestos disonantes con el tipo de utilitarismo que solía ser tradicional en la clase media. Más concretamente, la clase media vive ahora en un mundo: en el que las concepciones convencionales de la utilidad y la moralidad son cada vez menos viales; en el que las recompensas parecen a menudo tener poca relación con la utilidad o la moralidad de los hombres (o de las cosas); y en el que los 
hombres pueden salir adelante sin los talentos o habilidades convencionales necesarios en la vieja economía de la clase media centrada en la producción. En resumen: la nueva clase media se ha sensibilizado hacia las irracionalidades del moderno sistema de recompensas... La sociología de Goffman corresponde a las nuevas exigencias de una clase media cuya fe tanto en la utilidad como en la moralidad se ha visto gravemente debilitada. ... La nueva clase media busca hacer frente al debilitamiento de sus estándares convencionales de utilidad y moralidad retirándose de ambos y buscando fijar su perspectiva en estándares estéticos, en las apariencias de las cosas» (pp. 388-390).

Esta visión de Gouldner sobre la obra goffmaniana, visión sin duda brillante y en parte perspicaz, me parece un tanto parcial e injusta, en cuanto que considera que Goffman se limita a producir una sociología de la nueva clase media, sobre todo de la que está ligada (por su trabajo o por su consumo) a las grandes organizaciones burocráticas. Ya aludimos al comienzo de este trabajo a la crítica que Giddens formula a esta unilateral interpretación gouldneriana, que, muy goffmanianamente, tiende a quedarse en las «apariencias» de la obra de Goffman, no entrando en su mensaje último.

Llegado al final de este ya largo artículo, sólo me queda repetir, en una especie de final recapitulación, algo de lo que ya he ido diciendo. Considero que Goffman es uno de los grandes científicos sociales de la segunda mitad de nuestro siglo y, sin duda, el gran estudioso de la interacción cara-a-cara (él prefiere hablar del «orden de la interacción» o de la "co-presencia»). No parece admisible, claro, pretender autonomizar este orden de la interacción, como parece hacer Goffman. Aunque pienso que lo que en realidad hace Goffman es acotar un campo de estudio (el de la co-presencia), centrándose en lo que tiene de específico. Sin duda que en la situación de co-presencia, y como consecuencia de la interacción entre los actores, surgen muchas cosas. Sin duda que dicha situación tiene "una cierta» autonomía, habiendo en ella una creatividad constante. Sin duda que constituye una especie de «microcosmos» o de «microestructura social». Y sin duda que es legítimo que Goffman haga de este aspecto de la realidad social su centro de atención. Pero, claro, y como Goffman sabía bien, ésta es sólo parte de la historia. Sucede que los actores que interactúan no son seres abstractos, sino humanos rabiosamente concretos, históricos (socializados en una determinada sociedad y portadores de una determinada cultura). Sucede también que tienen distintos grados de poder, por lo que su capacidad de acción y las consecuencias de sus acciones son muy distintas. Y sucede también que ese orden de interacción está inserto en una macroestructura sociocultural (estando condicionado por ella) y que es, a su vez, productor de esa macroestructura. Aunque también es cierto, repito, que ese orden de interacción goza de bastante autonomía y que no es nada fácil, claro, determinar las conexiones entre ese orden micro y el orden macro, 
es decir: determinar cómo la macroestructura sociocultural condiciona la interacción cara-a-cara y cómo dicha interacción cara-a-cara reproduce y produce la macroestructura.

Por otra parte, si bien es cierto que la vida social tiene mucho de teatro, no es menos cierto que se trata de un "teatro-verdad», en el que están dramáticamente implicadas las vidas de los actores, que no son meros «actuantes», sino humanos llenos de sentimientos, que están siempre en juego en sus interacciones. De ahí que en la vida social no haya mera dramaturgia, sino auténtico drama.

De lo anterior se desprende que Goffman sólo nos cuenta (y lo hace muy bien) una parte de lo que en la vida social sucede: la de la interacción cara-acara, con su innegable especificidad y su relativa autonomía. Hay otra parte (la de las diferencias de poder, la de los sentimientos humanos, la del orden macro) que Goffman no cuenta ni pretende contar.

\section{BIBLIOGRAFÍA}

Blumer, H. (1972): «Action vs. Interaction» (recensión de Relations in Public, de E. Goffman), Society, 9 (abril), 50-53.

Burns, T. (1992): Erving Goffman, Routledge.

Carrithers, M., y otros (eds.) (1985): The Category of the Person, Cambridge University Press.

Collins, R. (1975): Conflict Sociology: Toward an Explanatory Science, Academic Press, N. York.

- (1988): Theoretical Sociology, Harcourt Brace Jovanovich, Inc.

DitTon, J. (ed.) (1980): The View from Goffman, MacMillan, Londres.

Drew, P., y Wootton, A. (eds.): Erving Goffman: An Interdisciplinary Appreciation, Polity Press.

Giddens, A. (1987): «Erving Goffman as a systematic social theorist», incluido en Social Theory and Modern Sociology, Stanford University Press, pp. 109-139.

Goffman, E. (1961): Asylums, Doubleday, N. York.

- (1967): Interaction Ritual, Doubleday, N. York.

- (1969): The Presentation of Self in Everyday Life, Allen Lane The Penguin Press, Londres.

- (1971): Relations in Public, Basic Books, N. York.

- (1974): Frame Analysis, Harper \& Row, N. Yor.

- (1981): Forms of Talk, Basil Blackwell, Oxford.

- (1983): «The interaction order», American Sociological Review, vol. 48, pp. 1-17.

Gouldner, A. (1970): The Coming Crisis of Western Sociology, Heinemann, Londres.

Habermas, J. (1981-1984): The Theory of Communicative Action, Beacon Press, Boston.

Lyman, S. M., y SCOTT, M. B. (1970): A Sociology of the Absurd, Appleton-Century-Crofts, N. York.

Martindale, D. (1960): American Society, Van Nostrand, Princeton.

MAUSS, M. (1985): "A category of the human mind: the notion of person; the notion of self", incluido en M. Carrithers y otros (eds.), The Category of the Person.

MÜNCH, R. (1994): Sociological Theory (from the 1920s to the 1960s), vol. 2, Nelson-Hall Publishers, Chicago.

Rosenberg, M. (1981): "The self-concept: social product and social force», incluido en M. Rosenberg y R. H. Turner (eds.): Social Psychology, Basic Books, N. York.

SEBASTIÁN DE ERICE, J. R. (1994): Erving Goffman (de la interacción focalizada al orden interaccional), Centro de Investigaciones Sociológicas, núm. 138, Madrid. 


\begin{abstract}
In this paper, Goffman is presented as one of the great social scientists of the second half of this century and, doubtless, the great scholar of face-to-face interaction (he prefers to talk of the "order of interaction» or the "co-presence»), although there are no grounds to autonomise this order of interaction as would appear to be Goffman's aim. The paper starts off by taking a look at Goffman's intellectual trajectory and the works it yielded. It then goes on to examine in some detail two of his most representative works: The Presentation of Self in Everyday Life and Frame Analysis. The author of this paper then studies daily interaction as a ritual, with special reference to conversation in terms of verbal interaction. Section five is devoted to the study of the self and section six to the theoretical scope of Goffman's work. The paper closes with some of the diverse criticisms which have been directed at Goffman. Because the fact of the matter is that Goffman only describes (and very well at that) part of what takes place in social life: face-to-face interaction with its undeniable specificity and its relative autonomy. There is another side (that of differences in power, that of human feelings, that of the macro order) which Goffman does not discuss or intend to discuss.
\end{abstract}

